\title{
Gestão socioambiental nas grandes cidades: por que olhar do Brasil para as iniciativas das megalópoles indianas?
}

Socio-environmental management in large cities: why look from Brazil to the initiatives of indian megalopolises?

Leonardo Mercher[a] (1)

[a] Universidade Federal do Paraná (UFPR), Departamento de Ciência Política, Curitiba, PR, Brasil.

Como citar: Mercher, L. (2019). Gestão socioambiental nas grandes cidades: por que olhar do Brasil para as iniciativas das megalópoles indianas. urbe. Revista Brasileira de Gestão Urbana, 11, e20180009. https://doi.org/10.1590/21753369.011.e20190009.

\section{Resumo}

Diante dos diversos modelos de gestão pública no mundo, é valido observar outras experiências em realidades socioambientais mais semelhantes às cidades brasileiras em desenvolvimento. No cenário do BRICS - Brasil, Rússia, Índia, China e África do Sul -, o presente texto identifica as três maiores cidades indianas, Mumbai, Déli e Bangalore, como uma possibilidade de difusão de políticas públicas às cidades brasileiras, dada a proximidade de fatores, como clima tropical, favelização, corrupção pública e desigualdade social. A hipótese levantada é de que a realidade indiana seria mais próxima à realidade brasileira do que as realidades europeias (incluindo a Rússia) ou a realidade chinesa, mas os meios de difusão da informação no Brasil pouco tratam das experiências indianas. Para testar a hipótese, faz-se a análise de dados econômicos, demográficos, sociais e ambientais de fontes governamentais e de organismos internacionais, como do BRICS, PNUD, UN-Habitat e Banco Mundial nos anos 2000 e 2010, bem como dos maiores think tanks no Brasil em Relações Internacionais: CEBRI e BRICS Policy Center. Como resultado, observa-se que os desafios das grandes cidades indianas e brasileiras são semelhantes, porém há pouco material em língua portuguesa nos think tanks de Relações Internacionais que orientam as práticas de gestores públicos brasileiros.

Palavras-chave: Cidades. Índia. Brasil. Política pública.

\begin{abstract}
In view of different models of public management in the world, it is worth to observe other experiences in socio-environmental realities more similar to the Brazilian cities in development. In BRICS scenario Brazil, Russia, India, China and South Africa - this paper identifies the three largest Indian cities, Mumbai, Delhi and Bangalore, as a possibility of diffusion of public policies to Brazilian cities besides proximity to factors such as slum, public corruption and social inequality. The hypothesis raised is that Indian reality would be closer to Brazilian reality than European realities (including Russia) or Chinese reality, but the means of diffusion of information in Brazil - International Relations think tanks - does not deal with Indian experiences. To test the hypothesis, the analysis of economic, demographic, social and environmental data
\end{abstract}


from governmental sources and from international organizations such as the BRICS, UNDP, UN-HABITAT and World Bank in the years 2000 and 2010, as well as the major think tanks in Brazil in International Relations: CEBRI and BRICS Policy Center. As a result, it is observed that the challenges of the great Indian and Brazilian cities are similar, but there is little material in Portuguese in the International Relations think tanks that could guide the practices of Brazilian public managers.

Keywords: Cities. India. Brazil. Public policy.

\section{Introdução: por que olhar para as cidades indianas?}

Em estudos sobre cidades nas Relações Internacionais, quando se busca compreender modelos de desenvolvimento local e identificar boas práticas de gestão e de políticas públicas, é preciso se questionar de onde o pesquisador irá partir e para onde irá olhar. Partindo da realidade das cidades brasileiras, fica aberta a segunda pergunta: para onde olhar? É comum que gestores públicos brasileiros (prefeitos e secretários) olhem para modelos de gestão urbana europeus e de outras nações desenvolvidas. Entretanto, as distâncias sociais, econômicas e estruturais de cidades em desenvolvimento às cidades desenvolvidas podem se tornar um grande desafio na implementação de modelos e práticas de gestão e políticas públicas. Diante desse cenário, é importante buscar experiências de gestão em cidades que possuem realidades socioambientais próximas. No caso das grandes cidades brasileiras, existem alguns desafios, como os índices de favelização, a corrupção governamental e a relação entre desenvolvimento e sustentabilidade.

Diante dessa problemática inicial, o presente artigo busca trazer alguns parâmetros que possam ampliar fontes de pesquisas futuras para além das cidades em nações desenvolvidas. Mas, diante do mundo, por que olhar para as grandes cidades indianas? Em primeiro lugar pelo conjunto de acordos de cooperação entre os Estados-membros do BRICS (Brasil, Rússia, Índia, China e África do Sul), que contemplam setores de suas economias nacionais e também financiamento de práticas de desenvolvimento socioambientais. Em segundo lugar por serem as cidades indianas, assim como as brasileiras, os maiores centros mundiais em áreas tropicais e em desenvolvimento, com índices políticos e socioeconômicos mais próximos do que a realidade africana, europeia ou norte-americana (com exceção da Cidade do México). Ou seja, a Índia reúne o maior número de cidades em alta densidade mundial (Figura 1) e em natureza socioambiental semelhantes às grandes cidades brasileiras. Portanto, a densidade demográfica se torna um critério de seleção - e até mesmo uma variável diante da aplicação de práticas de outras cidades. 


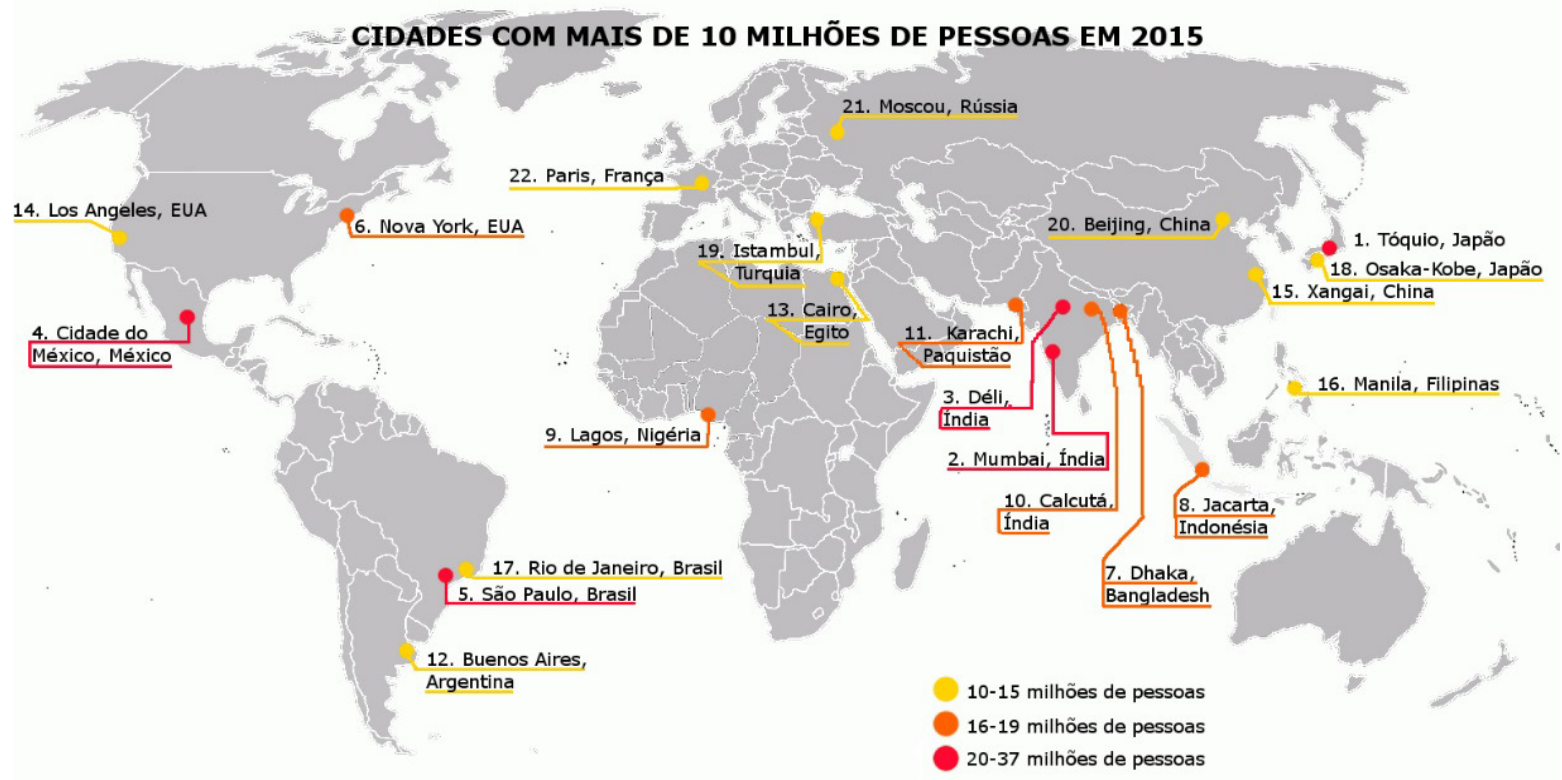

Figura 1 - Cidades ao redor do mundo com mais de 10 milhões de habitantes em 2015. Fonte: Annenberg Learner (2015).

Os índices demográficos (tamanho das cidades e sua densidade), dos setores econômicos e de produtividade (riqueza das cidades), do desenvolvimento humano (desafios sociais) e das proximidades culturais (valores sociais e dinâmica política) colocam-se como variáveis fundamentais à avaliação de exemplos de gestão pública entre as cidades. Por exemplo, as grandes cidades brasileiras, observando a primeira dimensão, superam em tamanho a maioria das cidades latino-americanas, norte-americanas e europeias (Figura 1). São Paulo, com 12.176.866 habitantes (IBGE, 2018), e Rio de Janeiro, com 6.688.927 de habitantes (IBGE, 2018), possuem dificuldades em encontrar referenciais de boas práticas de gestão local que se aproximem à realidade da alta taxa de densidade populacional e em um cenário de desigualdade social ao olhar para a Europa, por exemplo. As grandes cidades europeias, como Paris, com 2.152.000 de habitantes (City Mayors Statistics, 2018), Berlim, com 3.387.000 habitantes (Ibidem), e Barcelona, com 1.455.000 de habitantes (Ibidem), ficam muito abaixo da realidade populacional do Rio de Janeiro ou de São Paulo. Além do mais, cidades que se aproximam em população, como Londres, com 7.074.000 habitantes (Ibidem), e Nova Iorque, com 8.336.697 habitantes (Ibidem), não estão em níveis próximos de desenvolvimento humano (Figura 2), favelização (Figura 3), desenvolvimento econômico e faixa climática e seus respectivos desafios.

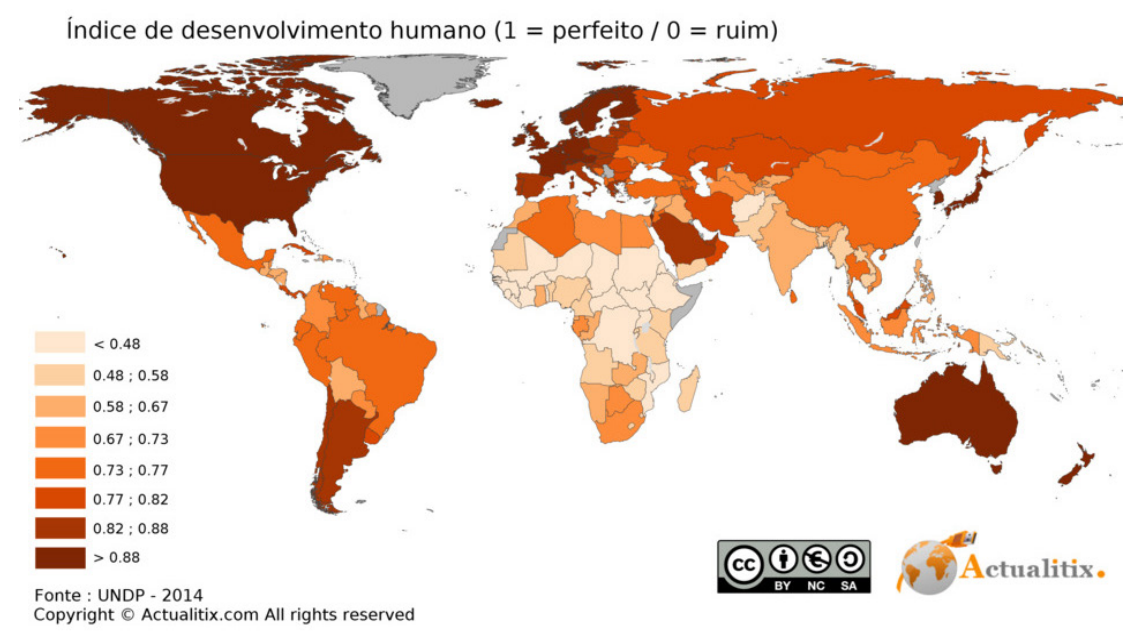

Figura 2 - Índice de desenvolvimento humano em 2014 (1 = perfeito / 0 = ruim). Fonte: Actualitix (2016). 
Mumbai, com 12.478.447 de habitantes (Governo da Índia, 2011), Déli, com 11.007.835 de habitantes (Ibidem), e Bangalore, com 8.425.970 de habitantes (Ibidem), são as três maiores cidades indianas. Segundo o Censo de 2010, a Região Metropolitana de São Paulo possui aproximadamente $11 \%$ da população vivendo em favelas, além de existirem bairros precários em infraestrutura e serviços básicos que não são contabilizados dentro da própria cidade, classificados de bairros de classe média baixa. Já a cidade do Rio de Janeiro supera proporcionalmente a Região Metropolitana de São Paulo, alcançando aproximadamente $22 \%$ de sua população em "aglomerados subnormais" (IBGE, 2010). Esses dados são bem diferentes das cidades europeias, mas não tão diferentes das cidades indianas (UN-Habitat, 2005): Mumbai alcança 55\% de sua população em habitações precárias, concentrada apenas em $6 \%$ de seu território total, onde a taxa de crescimento das favelas é maior do que a de todo o crescimento urbano da cidade. Como apresentado nas Figuras 2 e 3, de acordo com os dados e os informativos das Nações Unidas, a realidade europeia e das demais nações desenvolvidas não encara a alta complexidade dos atuais desafios da favelização urbana presentes na América Latina, na África e na Ásia.

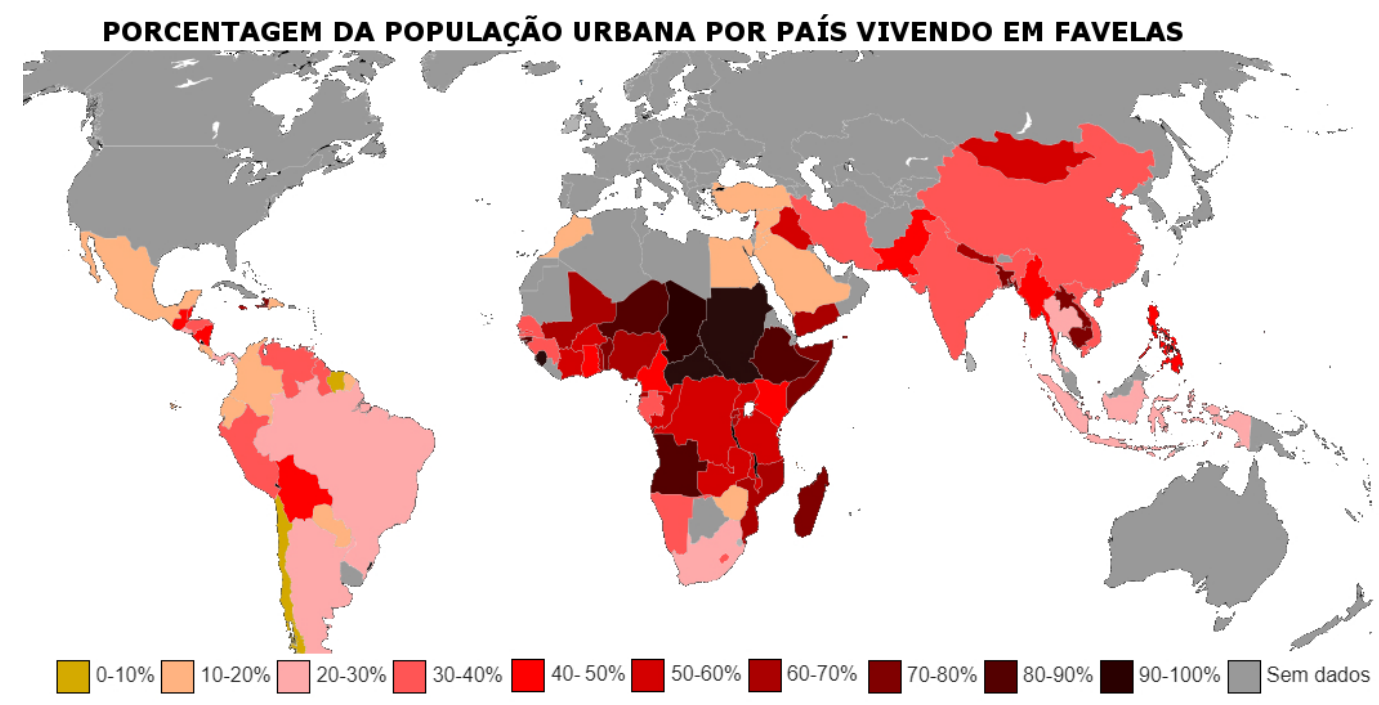

Figura 3 - Porcentagem da população urbana vivendo em favelas, 2005. Fonte: Programa das Nações Unidas para Habitação - UN-Habitat (2005).

Os dados das cidades brasileiras e indianas (Figura 3) esclarecem, ao menos, um eixo de desafios em comum: a alta densidade urbana e o desafio de planejamento local que possibilite à cidade melhores índices de desenvolvimento humano. A característica do crescimento urbano associado à baixa oferta habitacional é a origem primária da favelização. De acordo com Maricato (2000), as favelas abrigam populações mais vulneráveis socialmente ao desemprego, à violência e ao baixo acesso ao saneamento e aos serviços públicos fundamentais, como esgoto, transportes e sustentabilidade. Consequentemente, a favelização, ao mesmo tempo que se torna origem de muitos desafios da gestão local, também aponta para desafios primários, como a desigualdade social e a baixa capacidade da esfera pública de atender às necessidades de sua população. Contudo, não seria apenas os governos a fonte das origens desse processo. Como aponta Sassen (2011): "como escrevi recentemente nessa série Megacities, quanto maior a Cidade Global, maior será a Favela Global" 1 , ou seja, os processos econômicos e financeiros internacionais aceleram e intensificam a desigualdade social e, consequentemente, a favelização e os atuais desafios das cidades em desenvolvimento, como as favelas no Brasil e na Índia (Figura 4).

\footnotetext{
1 "As I wrote earlier in this Megacities series, the bigger the Global City, the bigger its Global Slum." (Sassen, 2011).
} 

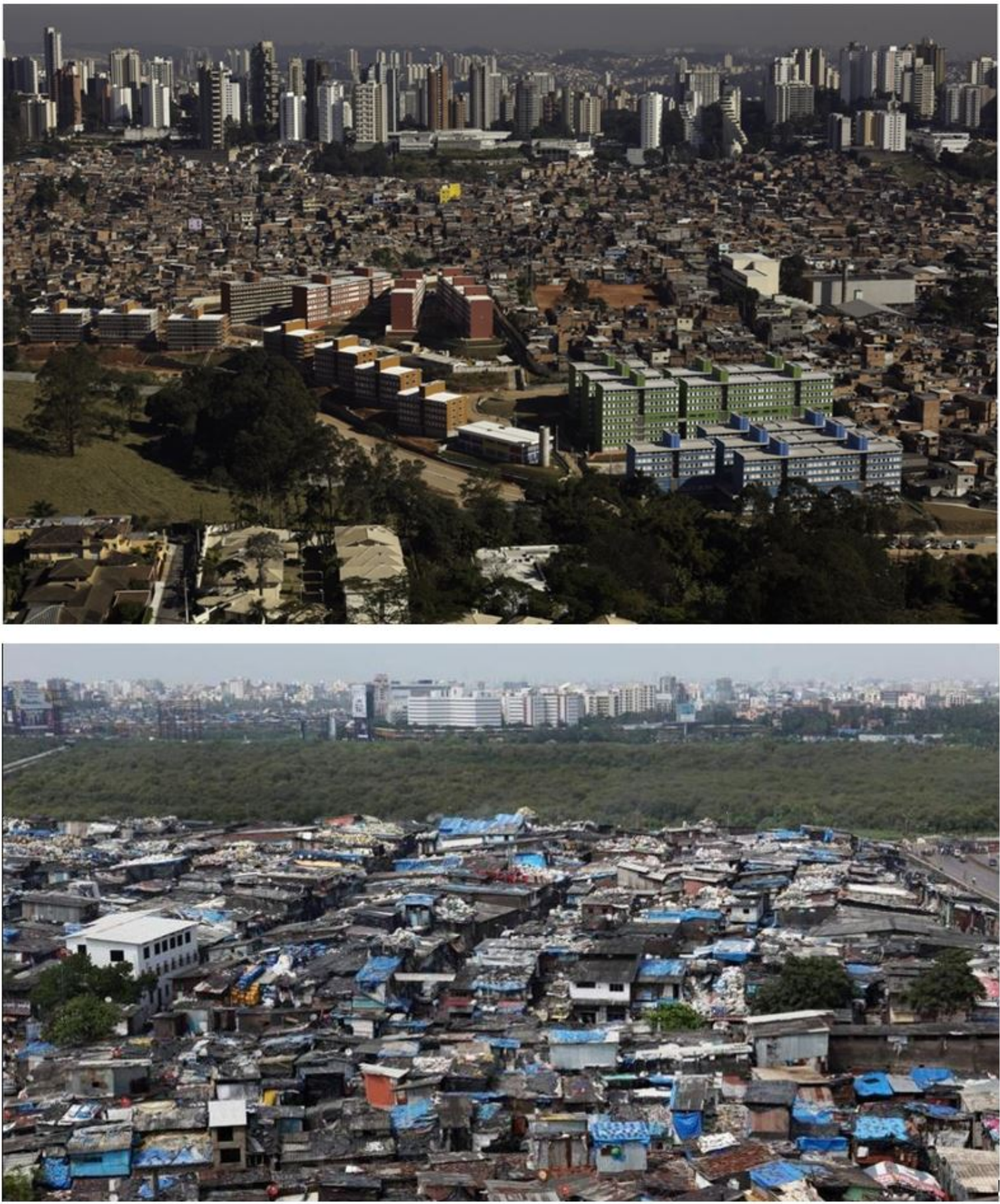

Figura 4 - Vista aérea de favelas em São Paulo (Brasil) e Mumbai (Índia). Fontes: (Esq.) São Paulo (2013) apud Maziviero \& Silva (2018) e (Dir.) Malik (2018).

É sabido que o tratamento de esgoto e água potável diminui os riscos de mortalidade infantil, doenças e degradação ambiental. No caso do saneamento básico e dos resíduos das cidades indianas, o relatório "Urban water supply and sanitation in Indian Cities" (PEARL, 2015) traz dados muito próximos aos das cidades brasileiras. A preocupação com o tratamento de esgoto e água potável, bem como resíduos e poluição de lençóis freáticos, rios e lagos indianos, trouxe experiências governamentais e da sociedade civil que fomentaram a concepção de desenvolvimento sustentável. Apesar de Nova Déli estar em uma situação aceitável em saneamento básico, assim como as cidades de Chandigarh, Mysore e Surat, aproximadamente 190 cidades estariam em situação de emergência (Idem, p. 7). Diante desse caso, será tratado mais adiante o caso da poluição do Lago Kaikondrahalli. 
No Brasil, a poluição da água por despejos urbanos (esgoto e lixo) é um problema que pauta a agenda pública há algumas décadas. A despoluição da Baía de Guanabara, da Lagoa Rodrigo de Freitas e das Lagoas da Barra da Tijuca (no Rio de Janeiro) ou ainda os problemas de abastecimento de água e despoluição dos Rios Tietê e Pinheiros (em São Paulo) demonstram desafios socioambientais muito próximos. Nesse cenário, as grandes cidades em desenvolvimento precisam lidar com menos recursos e maiores desafios, justamente por estarem crescendo em densidade populacional.

A preocupação ambiental fez com que Estados e também governos locais buscassem cooperar com a implementação dos Objetivos do Desenvolvimento Sustentável (ODS), em que as questões da água, da poluição e dos recursos à vida são tratados como prioritários. É possível encontrar nos sites das prefeituras das cidades brasileiras e indianas conteúdos de preocupação ambiental e busca pelo desenvolvimento sustentável. Mas o desafio ambiental não pode ser visto de forma separada do social, e é por isso que, ao longo desta pesquisa, é utilizado o termo socioambiental. Como tratar do saneamento básico de forma separada dos processos de favelização e moradia irregulares tão comuns nas grandes cidades em desenvolvimento? Além do mais, é preciso compreender que as questões socioambientais vinculadas à gestão pública esbarram nos desafios da corrupção.

Os índices de corrupção também interferem na proximidade e na sensibilidade dos gestores diante das necessidades da população. A corrupção, tanto na Índia como no Brasil, acabam por dificultar a realização e a finalização de muitas práticas públicas. De acordo com a Transparência Internacional (Figura 5), Brasil e Índia estão muito próximos em suas posições de percepções sobre a corrupção existente em seus governos e suas sociedades.

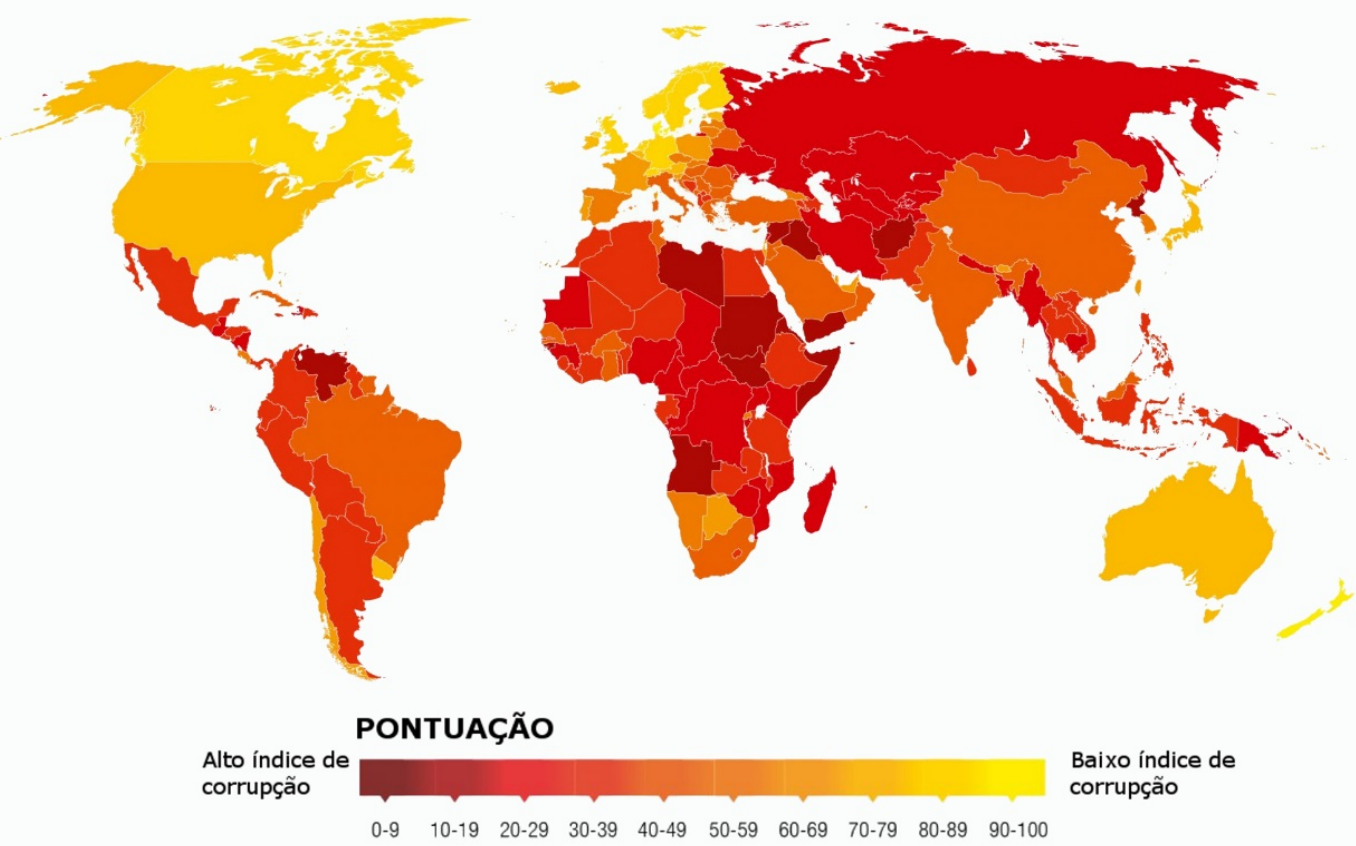

Figura 5 - Índice de percepção de corrupção, 2014. Fonte: Transparency International Georgia (2014).

A percepção de corrupção pode ser uma possível explicação para a demanda social por diminuir a presença do Estado na gestão dos diversos setores sociais, como a economia, e, em certa medida, poderia até ser compreendida como uma explicação para a existência de modelos neoliberais de desenvolvimento - em que os governos passam para a sociedade e a iniciativa privada a responsabilidade de suas políticas públicas. Na perspectiva de Sassen (2011), esse repasse de responsabilidades da gestão urbana do setor público para o privado seria o próprio enfraquecimento de muitas cidades ao redor do mundo com as crises migracionais urbanas e a globalização financeira, que trariam desafios tão grandes para gestores locais que as cidades não teriam condições de solucioná-los sozinhas. Diante desse cenário de desconfiança, os governos podem seguir caminhos de fiscalização, deixando as práticas nas mãos da 
iniciativa privada (locais e internacionais), de organismos internacionais (PNUD, UN-Habitat, Banco Mundial etc.) ou da própria população em iniciativas da sociedade civil (tanto ONGs locais como internacionais, por exemplo).

Já acerca dos modelos de desenvolvimento adotados pela gestão pública de cidades brasileiras, é possível identificar, ao menos, dois grupos de padrões de práticas e orientações: o grupo de padrão neoliberal e o grupo de padrão cooperativo (Mercher et al., 2018). De modo geral, na realidade brasileira, as cidades tendem a receber ou a iniciar projetos de características neoliberais - desenvolvimento social como consequência do desenvolvimento comercial - ou de características mais cooperativas desenvolvimento social tão importante quanto os demais (Quadro 1).

Deve-se observar que os modelos neoliberais não impedem a cooperação, mas possuem ênfase maior na autonomia das cidades e na atração de recursos, especialmente de outras cidades e agentes externos desenvolvidos (que possuem capital de investimento), como das organizações internacionais do Sistema ONU. As cidades brasileiras tenderiam a buscar no cenário internacional recursos financeiros, aumentar a sua visibilidade em busca de recursos comerciais e do turismo, bem como aprender com cidades desenvolvidas algumas práticas de gestão urbana pontuais, ou seja, segmentadas em setores, como transportes, despoluição, moradia popular, acessibilidade e combate à criminalidade.

Quadro 1 - Quadro conceitual de modelos de desenvolvimento local

\begin{tabular}{|c|c|c|}
\hline & MODELO NEOLIBERAL & MODELO COOPERATIVO \\
\hline $\begin{array}{l}\text { Fonte } \\
\text { epistêmica }\end{array}$ & $\begin{array}{l}\text { Neoliberalismo econômico. } \\
\text { Práticas de cidades estadunidenses e } \\
\text { europeias (anos 1980-1990). } \\
\text { Grupo Barcelona, Eurocities etc. }\end{array}$ & $\begin{array}{l}\text { Cooperação Sul-Sul. } \\
\text { Produção acadêmica de experiências regionais. } \\
\text { Quadrado do desenvolvimento sustentável local } \\
\text { de John Hawkes. }\end{array}$ \\
\hline Objetivos & $\begin{array}{l}\text { Criação de consenso político para um } \\
\text { grande modelo de desenvolvimento. } \\
\text { Superação de crises econômicas. } \\
\text { Desenvolvimento econômico como } \\
\text { mantenedor do desenvolvimento social. } \\
\text { Redução de custos e responsabilidades } \\
\text { sobre políticas sociais. } \\
\text { Parcerias com a iniciativa privada na } \\
\text { execução de políticas sociais. }\end{array}$ & $\begin{array}{l}\text { Políticas fundamentadas na diversidade } \\
\text { sociocultural e econômica local. } \\
\text { Incentivo a trocas e difusão de políticas públicas } \\
\text { entre cidades com realidades próximas. } \\
\text { Fortalecimento da cooperação. } \\
\text { Defesa da autonomia do local em questões } \\
\text { distantes aos interesses dos governos nacionais } \\
\text { (princípio da subsidiariedade). } \\
\text { Desenvolvimento diversificado advindo do bem- } \\
\text { estar social em sua pluralidade. }\end{array}$ \\
\hline Práticas & $\begin{array}{l}\text { Privatização e terceirização. } \\
\text { Adequação das cidades aos cinco } \\
\text { mercados (imobiliário, entretenimento, } \\
\text { turismo, comércio internacional e } \\
\text { financeiro). } \\
\text { Substituição de planos diretores por planos } \\
\text { estratégicos. } \\
\text { Participação em concursos e eventos } \\
\text { competitivos para atração de capital } \\
\text { estrangeiro. } \\
\text { Visibilidade em grandes eventos } \\
\text { internacionais em detrimento da } \\
\text { cooperação nos espaços cooperativos } \\
\text { locais/regionais. } \\
\text { Discurso da crise econômica para legitimar } \\
\text { modelos de baixa proteção social. }\end{array}$ & $\begin{array}{l}\text { Incentivo às iniciativas sociais, políticas e } \\
\text { econômicas fundamentadas na experiência } \\
\text { local. } \\
\text { Pluralidade de políticas públicas para } \\
\text { desenvolvimento local. } \\
\text { Proteção social. } \\
\text { Adequação da cidade ao desenvolvimento de } \\
\text { economias locais sustentáveis. } \\
\text { Complementariedade de produção. } \\
\text { Fomento à cooperação descentralizada. } \\
\text { Proteção sociocultural em sua pluralidade. } \\
\text { Compreensão de que crises econômicas não } \\
\text { necessariamente advêm ou serão solucionadas } \\
\text { só a partir da gestão local. }\end{array}$ \\
\hline $\begin{array}{l}\text { Cidades } \\
\text { praticantes }\end{array}$ & Barcelona, Milwaukee, Rio de Janeiro. & Foz do Iguaçu, Nova Déli, Porto Alegre. \\
\hline
\end{tabular}

Fonte: Mercher et al. (2018).

A partir da compreensão de que nas grandes cidades brasileiras predominam as práticas neoliberais de gestão urbana - o desenvolvimento social (e ambiental) advém do sucesso da administração financeira e do sucesso econômico -, é possível compreender o desafio em observar modelos de nações em 
desenvolvimento. Com raros casos, como os teleféricos de Bogotá, replicados na cidade do Rio de Janeiro, as cidades brasileiras poderiam observar e avaliar boas práticas indianas.

Dessa forma, o presente artigo analisará experiências locais indianas e suas possibilidades de difusão entre cidades de países em desenvolvimento - e não necessariamente uma análise de caso de difusão já realizado, mas sim seu potencial. A relevância desse tipo de pesquisa e de tratamento dos dados encontra-se na busca por soluções em realidades semelhantes às brasileiras que são pouco observadas, como os dados mais adiante dos think tanks ${ }^{2}$ brasileiros irão apontar.

Enquanto difusão, é utilizado o conceito de Acharya (2004), que seria a capacidade de ideias se espalharem e mudarem o comportamento e o futuro dos agentes internacionais. Reconhece-se que existem mais pesquisadores sobre o tema difusão em outras áreas, como (Stone, 2012), com "Transfer and Translation of Policy", e Pereira et al. (2018), com "A governança facilitada no Mercosul: transferência de políticas e integração nas áreas de educação, migração e saúde", mas foram aplicados os preceitos de Acharya por se enquadrarem melhor em um recorte de problemática internacional mais construtivista e pós-colonialista de localização na Ásia.

A partir do processo de localização (localization) de Acharya (2004), a difusão de ideias passa a ser compreendida como dependente da sensibilidade e da disponibilidade dos agentes (no caso, as cidades brasileiras) em descobri-las. Mas, para isso, seria preciso ter o acesso às ideias, o que poderia, em uma percepção mais normativa, materializar-se em normas, regimes, organismos internacionais e think tanks. Os estudos de Acharya, bem como o de Sánchez (2001), demonstram a importância de se estudar práticas locais fora da própria realidade para que se possa entender o cenário internacional e diversificar a busca por boas práticas. Ao se limitar apenas aos estudos sobre processos de difusão já ocorridos, pode-se cair em textos descritivos que reforçariam a relação colonizador e colonizado, especialmente, como aponta Sánchez (2001), se, em sua maior parte, as boas práticas advêm de cidades desenvolvidas para atender aos mercados globais de cidades.

Por isso, a presente pesquisa busca valorizar experiências de gestão pública sob a ótica pós-colonialista: buscar soluções aos desafios brasileiros e boas práticas em ex-colônias em desenvolvimento, muito mais do que analisar agentes difusores e seus processos. Por isso, é preciso promover a divulgação de boas práticas que fogem do eixo de mercado de cidades, como critica Sánchez (2001), tornando este artigo como veículo de difusão. Com essa orientação teórica, serão vistas, a seguir, algumas boas práticas de gestão local indianas para que, ao final, seja levantada a crítica à lacuna dos think tanks brasileiros enquanto possíveis meios de difusão dessas ideias (e práticas) no Brasil.

\section{Algumas experiências indianas na gestão urbana no âmbito socioambiental}

Em cidades grandes, como as indianas e brasileiras, problemas comuns podem resultar em análises comparadas e trocas de experiências de boas práticas. Práticas, como as políticas públicas e as iniciativas da sociedade civil organizada, surgem para responder a questões locais em realidades de alta densidade demográfica e baixa distribuição de renda e recursos, por exemplo, as questões advindas de favelização, transportes, segurança pública e alimentar, poluição e gênero. Na presente seção, faz-se uma exposição de algumas práticas indianas que dialogam com desafios muito semelhantes ao Rio de Janeiro e a São Paulo. Em busca de fontes de boas práticas indianas (a partir de desafios comuns entre as realidades indiana e brasileira), é possível encontrar alguns resultados já realizados, como o projeto SETUP (2009) (Social Exclusion, Territories and Urban Policies: a comparision between India and Brazil).

\footnotetext{
${ }^{2}$ Think tank, também conhecido como grupo de conhecimento ou fábrica de ideias, seria uma instituição, como universidades e ONGs, que produz conhecimento sobre a realidade e difunde suas ideias e seus valores para os demais agentes praticarem. Por exemplo, o CEBRI, enquanto instituição de pesquisa em Relações Internacionais que se autodenomina um think tank, produziria publicações e seminários que se difundiriam em outras instituições de conhecimento e de gestão pública, orientando as práticas dos gestores públicos, desde prefeitos até diplomatas e chefes de Estados.
} 
Desenvolvido por diversos pesquisadores de instituições ao redor do mundo, sendo liderado pela professora antropóloga Marie Caroline Saglio Yatzimirsky (Instituto National des Langues et Civilisation Orientales, Paris, França), o projeto Setup trouxe análises comparadas entre Brasil e Índia no que se refere ao crescimento e aos desafios das cidades. Em observações sobre o desenvolvimento das cidades indianas, especialmente no que tange à favelização, a pesquisadora, com a demógrafa Véronique Dupont (Universidade Paris 1), estabeleceu a seguinte observação:

A população das terras ocupadas pelos posseiros em Delhi foi contida numa proporção muito menor do que em Mumbai. A capital do país demonstra, de certo modo, uma tolerância menor em relação às favelas. Em Mumbai, até os anos 1980, o Estado atuou principalmente como fornecedor de habitações por meio da urbanização básica, no que se refere às favelas notificadas. Em Delhi, o reassentamento sem habitação prevaleceu. Desde os anos 1990, as autoridades de Mumbai mudaram seu papel e tornaram-se facilitadores, habilitando outros parceiros privados (construtores e promotores) e ONG a desempenhar um papel maior na execução de programas relacionados com favelas. Os atores privados em Mumbai desempenham uma parte que eles não possuem em Delhi, onde o setor público é muito mais significativo (como proprietário de terra e tomador de decisão). Além disso, Delhi é a sede do governo da União e da Suprema Corte, enquanto em Mumbai, a intervenção de órgãos internacionais (especialmente o Banco Mundial) também é importante para explicar a elaboração de políticas. De um modo geral, parece que o processo de tomada de decisão em Mumbai é compartilhado - ou pelo menos influenciado - por atores em número mais variado do que em Delhi; essa configuração, contudo, facilita a interferência de interesses privados, bem como a da corrupção (Dupont \& Saglio-Yatzimirsky, 2009, p. 298).

Fica claro que o modelo implementado em Mumbai a partir dos anos 1990 é o neoliberal de desenvolvimento (Quadro 1), em que, por meio da cooperação, diversos agentes privados assumem para si uma responsabilidade dos governos e das instituições públicas. Como as autoras mencionam, a menor presença do governo em Mumbai pode ser uma das variáveis explicativas para a elevação da favelização e da corrupção. A corrupção, tanto na Índia como no Brasil, acaba por dificultar a realização e a finalização de muitas práticas públicas. De acordo com a Transparência Internacional (Figura 5), Brasil e Índia estão muito próximos em suas posições de percepções sobre a corrupção existente em seus governos e suas sociedades. Mas, ainda nesse cenário, é possível identificar práticas de fácil replicabilidade e de bons resultados para outras realidades em desenvolvimento no mundo - o que reforça a ação cooperativa, e não apenas autônoma e competitiva, das cidades.

Experiências indianas com traços do padrão mais cooperativo e de responsabilidade social podem ser vistas no relatório "Good Pratices: resouce book 2015" (PNUD \& Government of India, 2015). Nesse documento, existe o registro das principais boas práticas realizadas na Índia, em natureza mista de práticas neoliberais e cooperativas, que receberam reconhecimento internacional (Sistema ONU), como: o projeto SAFAR (System of Air Quality Forecasting and Research in metropolitan cities) em Déli e Mumbai; o projeto Dilli Annashree Yojna: Food Security for the vulnerable in Delhi; a restauração do Lago Kaikondrahalli em Karnataka (Bangalore); o projeto KIDROP (Karnataka Internet Assisted Diagnosis of Retinopathy of Prematurity) em Bangalore, entre outros.

Sobre o projeto SAFAR, que buscava melhorar a qualidade do ar nas regiões metropolitanas, como em Déli, é uma iniciativa do governo nacional da Índia que criou um órgão para acompanhar indicadores de qualidade do ar nas regiões metropolitanas e das mudanças climáticas, como possíveis desastres naturais (em análises de 48 até 72 horas). Com acesso por universidades, hospitais e outras instituições locais, possibilitava aos atletas e aos médicos e outros profissionais da saúde e segurança pública, por exemplo, criar planos e práticas para combater e amenizar doenças respiratórias e planos de contenção (PNUD \& Government of India, 2015, p. 95).

Inicialmente aplicado nas Regiões Metropolitanas de Pune e Déli, o SAFAR também foi estendido à Região Metropolitana de Mumbai. O projeto foi reconhecido pela Organização Meteorológica Mundial (WMO) como uma boa prática e replicado em diversas outras regiões, não apenas por trazer indicadores, mas também por conseguir prever e divulgar suas informações de forma simples e acessível à população 
(PNUD \& Government of India, 2015, p. 95). As informações técnicas do sistema alimentam diversos canais de avisos de acordo com o público, variando de hospitais até espaços públicos (Figura 6). A medição de poluição, radioatividade, raios UV e clima passa a orientar as práticas dos cidadãos, o que pode contribuir muito para regiões para além da Índia.

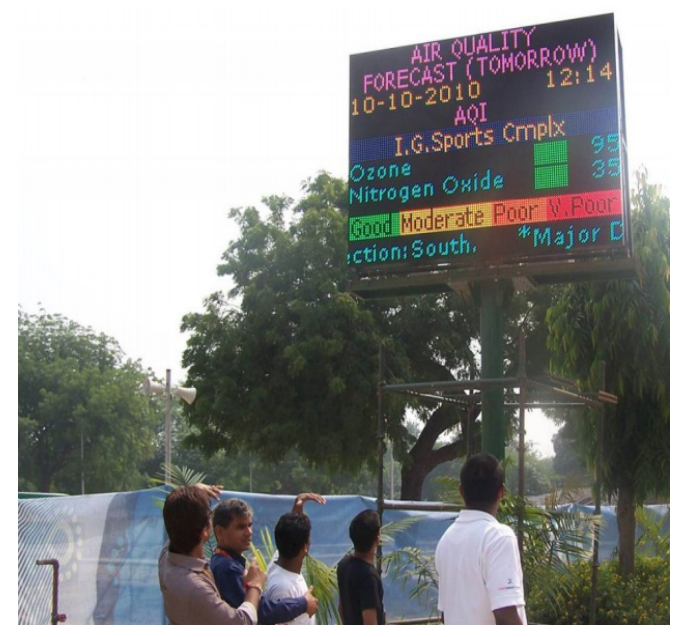

Figura 6 - Disposição do SAFAR ao público. Fonte: WMO (2019).

A replicabilidade do projeto SAFAR, segundo o próprio projeto, exige a participação da população local, dos governos e das instituições para contribuir com a compreensão das informações (conscientização populacional sobre os riscos de altos índices de UV e poluição e o que fazer nesses momentos). Como os custos são baixos em relação ao alto alcance da população, consegue, por utilizar diversos meios, superar informativos em jornais ou canais de televisão. Disponíveis em painéis eletrônicos em vias públicas, sites diversos, aplicativos para celulares e centrais telefônicas, dialoga com a alta densidade urbana e com os variados públicos da região, além de elementos visuais de fácil compreensão (cores e símbolos para os cidadãos não leitores do inglês). Cidades que já possuem redes de sinais de trânsito e painéis eletrônicos informativos (como sobre fluxos de trânsito), por exemplo, facilmente aplicariam o projeto em suas áreas urbanas.

Já o projeto Dilli Annashree Yojna (DAY), que visa segurança alimentar de famílias em risco social (vulneráveis, segundo o DAY), tem como principal foco a distribuição de ajuda às mulheres mais velhas das comunidades (Figura 7). Realizado em Déli, o projeto DAY busca preencher lacunas de moradores que não são beneficiados pelos programas de seguro social indiano. Como a migração para Déli é alta, a favelização aumenta, então diversas famílias acabam sem a documentação adequada para se inscrever nos programas do governo ou possuem um nível baixo de alfabetização, dificultando os trâmites burocráticos. Para atender a esses cidadãos, o projeto DAY distribui valores em contas cidadãs para gasto com grãos e açúcar diretamente aos indivíduos identificados (DBT - Direct Benefits Transfer) por meio de uma rede de agentes governamentais (como o Departamento Alimentar e a Autoridade de Identificação Única da Índia), empresariais (como bancos parceiros) e sociais (representações de gênero locais e as próprias mulheres beneficiadas, como idosas, mulheres transexuais e viúvas). 0 processo funciona pela identificação preferencial de mulheres idosas em famílias de alta vulnerabilidade social, seu cadastro direto nos centros de pesquisa de gênero locais e a distribuição dos recursos para alimentos.

Inicialmente as listas (identificação dos vulneráveis) foram feitas de porta em porta por órgãos de Déli (The Mission Convergence of the Government of the National Capital Territory of Delhi - GNCTD) e organizações não governamentais em 2008 e 2010, com base em três critérios: vulnerabilidade de localização (como famílias sem abrigo ou em residências precárias), vulnerabilidade social (idade, sexo, grupos estigmatizados, dificuldades físicas, órfãos etc.) e vulnerabilidade ocupacional (empregos arriscados ao físico e à mente, domésticos, estigmatizados e precários). 0 projeto já ultrapassou mais de mil beneficiados (PNUD \& Government of India, 2015, p. 125) 


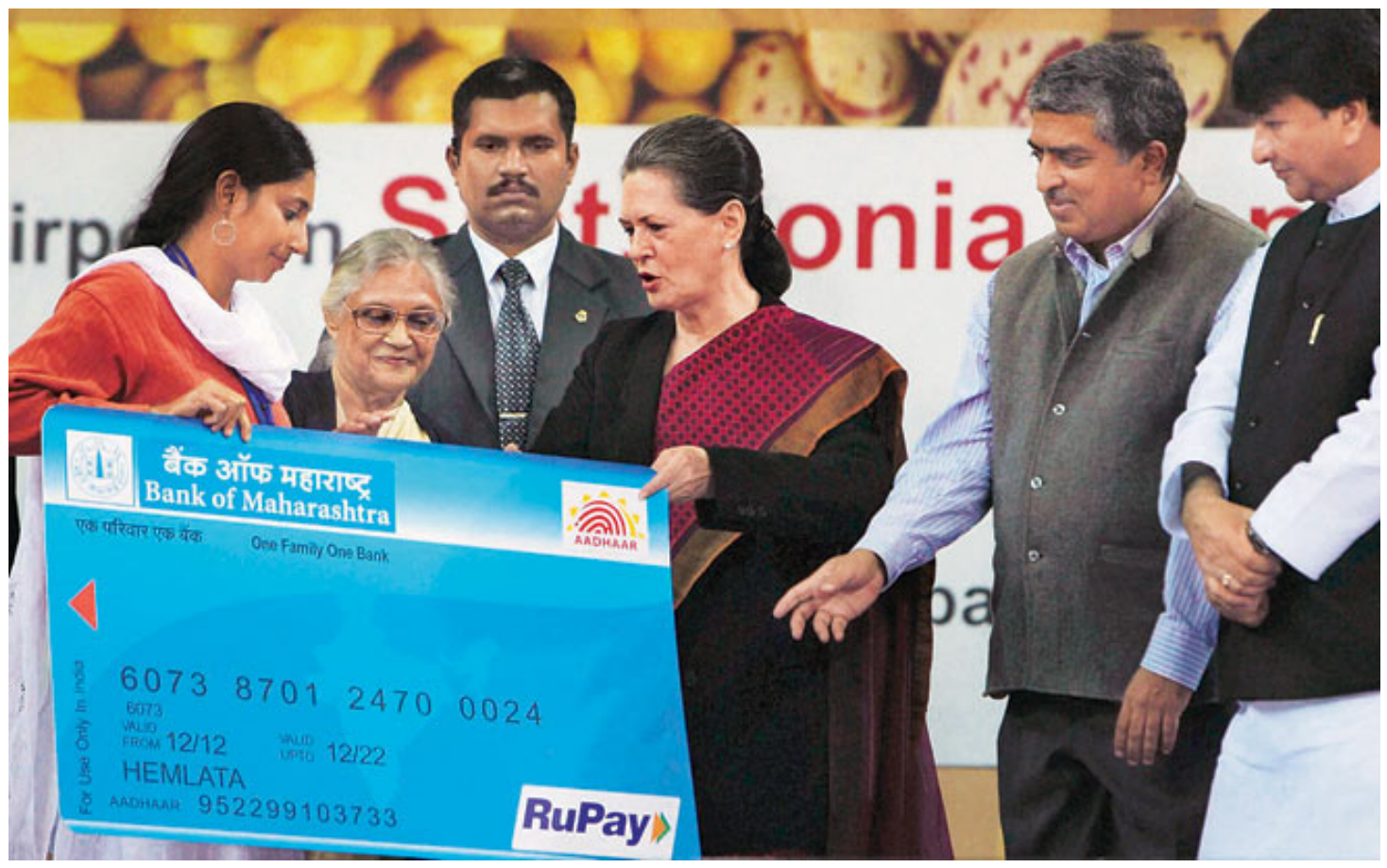

Figura 7 - Entrega comemorativa do auxílio DAY em 2013. Fonte: India Today (2013).

O grande desafio de identificar, cadastrar e transferir o auxílio estava em não identificar endereços, visto que muitas dessas mulheres moravam nas ruas ou em favelas com suas famílias, sem numerações oficiais. Além disso, a grande maioria não possuía contas bancárias, e, para superar ambos os desafios, o trabalho em rede entre o governo local, as instituições nacionais de identificação, os bancos parceiros e os Centros Regionais de Gênero (GRC) acompanhavam os atendidos constantemente, inclusive ao abrir as contas bancárias. A presença de mulheres mais velhas como parte desses centros da própria localidade facilitou a descentralização das práticas e aumentou a eficiência do projeto, penetrando em malhas sociais nas quais o Estado tinha dificuldades de se fazer presente.

Dessa forma, a prática assegura o direito a minorias e indivíduos vulneráveis, como nas questões de gênero (expectativa de vida, violência sexual, preconceitos etc.), tão comuns em muitas outras partes do mundo (PNUD \& Government of India, 2015). Nesse projeto, a ideia central de trabalho em conjunto com a própria população local em áreas de risco social facilita a penetração de políticas públicas, especialmente quando as ferramentas institucionais não conseguem se fazer funcionar, por exemplo, ao não identificar os habitantes em favelas para registro ou repasse do auxílio.

A ação em redes de múltiplos agentes também pode ser vista em outros exemplos, como na restauração do Lago Kaikondrahalli, em Karnataka (cidade de Bangalore). Também reconhecido pelo Programa das Nações Unidas para o Desenvolvimento (PNUD) como boa prática, a despoluição do lago foi resultante da ação coletiva entre governo e moradores locais. Tendo começado a secar em 2003 por bloqueios de construções urbanas e lixo ao seu redor (Figura 8) e ter se tornado um polo de malária em 2007 (Nagendra, 2016), o lago sensibilizou a população local e as autoridades governamentais. 


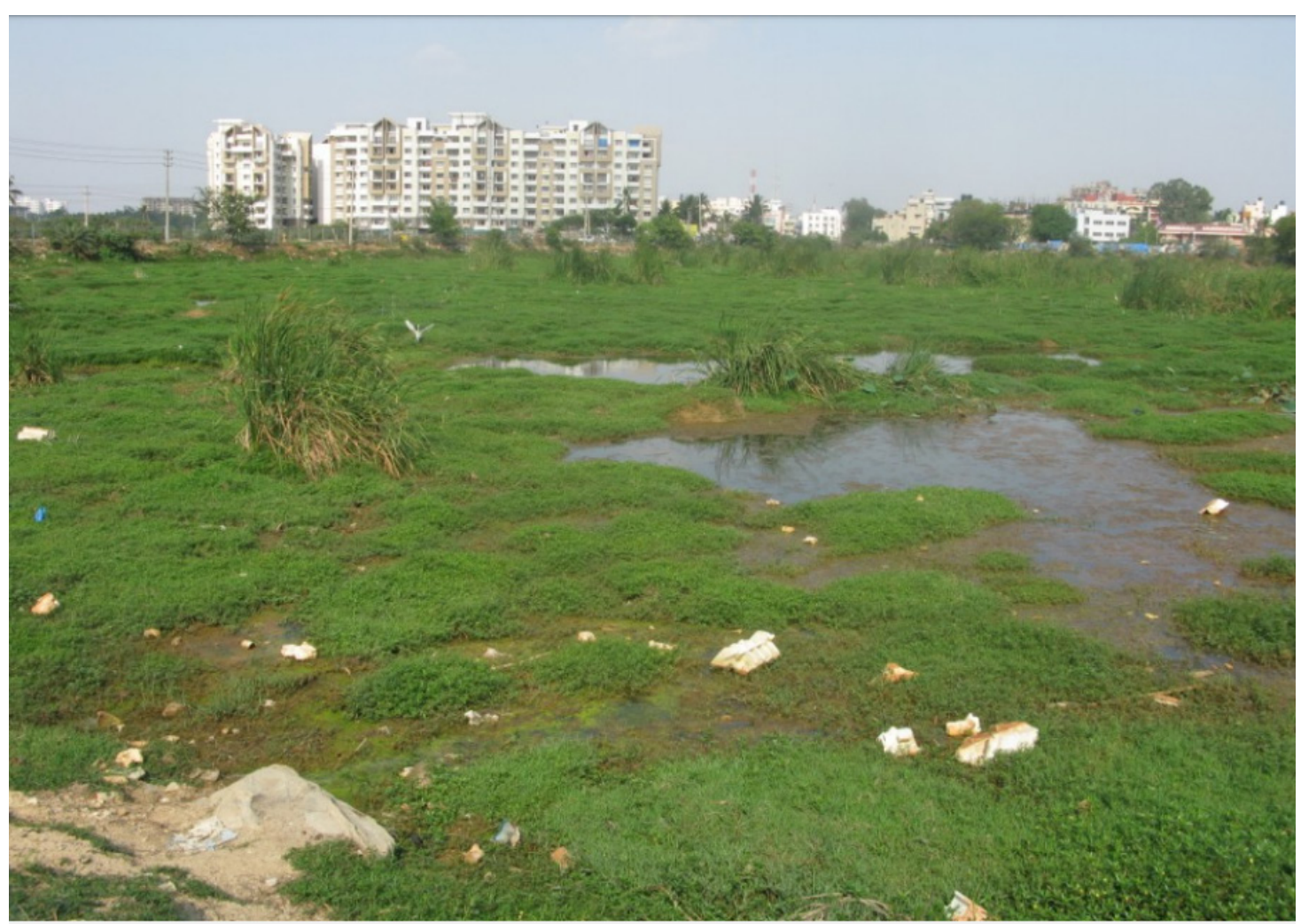

Figura 8 - Assoreamento e polvição do Lago Kaikondrahalli. Fonte: Nagendra (2016).

Contudo, projetos anteriores em outros lagos da cidade de Bangalore foram frustrados por denúncias de corrupção, o que dificultava novas iniciativas semelhantes para recuperar o Lago Kaikondrahalli. Mas a situação crítica de saúde e ambiental fez com que o governo cercasse a área para impedir a sua degradação e, posteriormente, investisse em infraestrutura e apoiasse as iniciativas dos moradores. Segundo o PNUD, a contribuição desse caso é a coordenação entre governo local e a fiscalização e o uso consciente da população (PNUD \& Government of India, 2015). Depois das iniciativas populares, como a produção de documentários e limpeza do entorno, o governo decidiu contribuir com apoio ao "rejuvenescimento" do lago (Figura 9). Ao final dos anos 2000, agências governamentais passaram a fiscalizar a área, limpar o lago e conscientizar a população local para o uso recreativo do local. A recuperação da fauna e da flora bem como a conscientização da população contribuíram para a sua recuperação gradual. A constante realização de eventos populares na região também serve para a apropriação e a monitoria da cidade e dos moradores locais de um patrimônio de todos. 

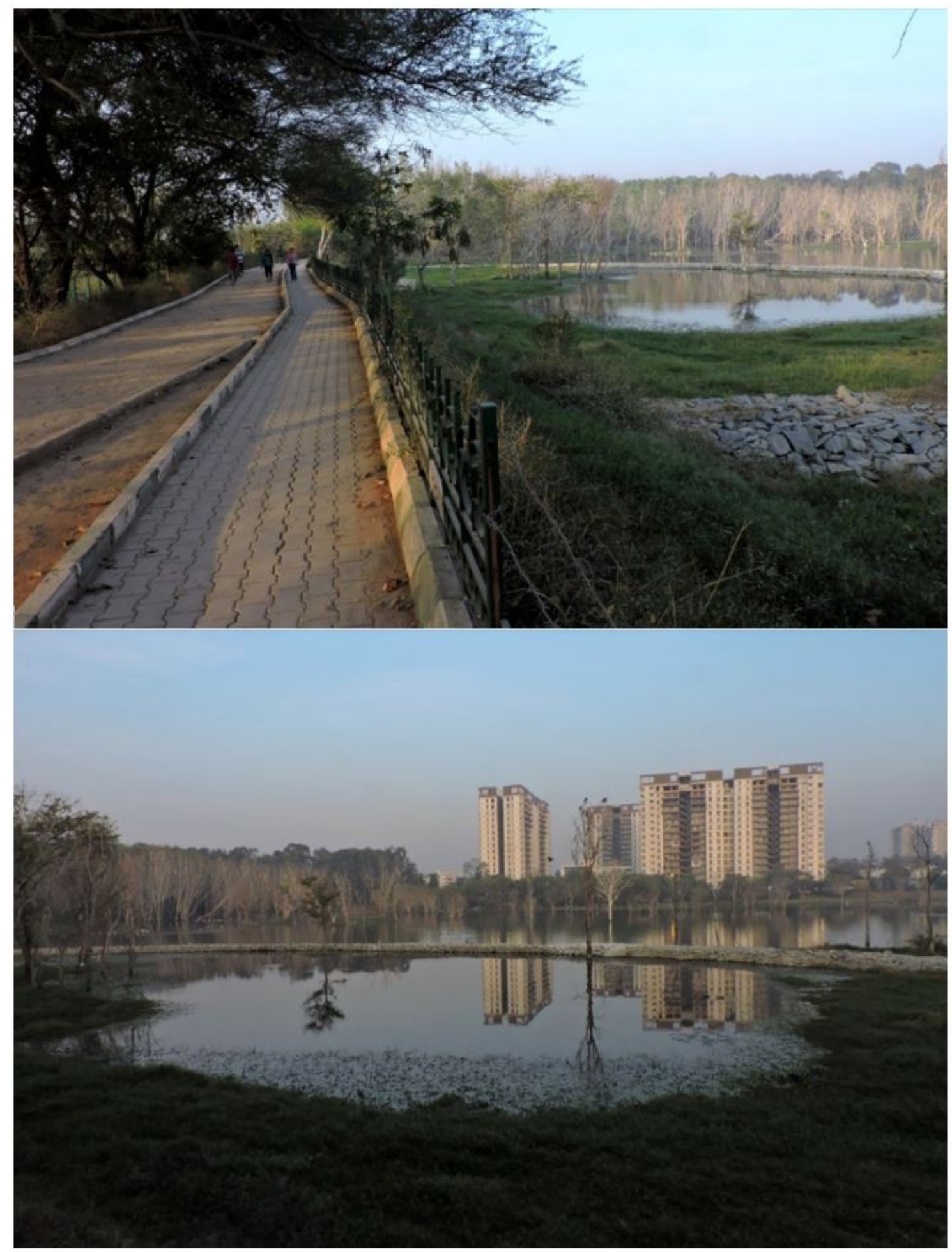

Figura 9 - Recuperação do Lago Kaikondrahalli. Fonte: Nagendra (2016).

No caso do lago, entretanto, os esgotos clandestinos dos condomínios de prédios residenciais podem retroceder a conquista (PNUD \& Government of India, 2015). Por isso, o presente caso demonstra que muitas das 651 iniciativas, por maior sucesso que possam obter, precisam de ações constantes, mas nem sempre apenas do poder público, mas da própria população local. Nesse caso, a conscientização da população contribui para a fiscalização e a boa utilização da região, diminuindo custos de constantes intervenções públicas, como nos surtos de malária. 
Por fim, a última boa prática indiana reconhecida internacionalmente é o projeto KIDROP (Karnataka Internet Assisted Diagnosis of Retinopathy of Prematurity), também em Bangalore, em que investimentos em tecnologia e treinamento de profissionais possibilitaram a diminuição da perda de visão em nascidos prematuramente. Iniciou em 2009 como um programa universitário que atendeu, até 2015, mais de 17.800 crianças na região de Karnataka. 0 projeto é uma parceria mista entre o governo de Karnataka (Bangalore), o Ministério da Saúde, a Missão Nacional Rural (governo indiano), o Instituto de Oftalmologia Narayana de Pós-Graduação (universidade) e a i2i TeleSolutions (empresa). Utilizando celulares e redes de internet móvel, é possível, com os aplicativos desenvolvidos, concluir exames oftálmicos em crianças recém-nascidas na região.

Por ser simples e de fácil replicabilidade, o governo indiano e o PNUD incentivam sua popularização, especialmente em regiões onde famílias não possuem acesso ao acompanhamento pré-natal e aos primeiros meses de nascimento da criança em redes públicas de saúde (PNUD \& Government of India, 2015). Como uma ação da saúde, da mesma maneira que as demais mencionadas em questões ambientais, sociais e climáticas, as iniciativas locais indianas reconhecidas por organismos internacionais também podem ser fonte de difusão de ideias para as práticas locais de outras cidades ao redor do mundo.

Dessa forma, as iniciativas indianas aqui apontadas reproduzem alguns dos anseios de cidades brasileiras em superar desafios semelhantes na esfera socioambiental. Questões, como a poluição do ar em São Paulo, a poluição lagunar no Rio de Janeiro, a dificuldade das políticas públicas de penetrar nos bairros mais periféricos, associam-se aos exemplos indianos aqui escolhidos a partir do relatório do PNUD 2015 sobre as boas práticas indianas. Todavia, o fato de se assemelharem em desafios não significa que as cidades brasileiras estão em contato com essas experiências indianas, muito menos que esses exemplos possuem ampla divulgação no Brasil.

\section{Desafios da difusão indiana às grandes cidades brasileiras}

A Índia possui práticas locais que são reconhecidas como soluções positivas pelo Sistema ONU. Sua realidade de problemas, assim como nas cidades em desenvolvimento ao redor do mundo, também facilitaria a proximidade de desafios e soluções encontradas possíveis de maiores êxitos. Rio de Janeiro e São Paulo possuem índices semelhantes de favelização, desafios ambientais e de corrupção e enfraquecimento diante dos grandes desafios que surgem com a globalização na esfera local. Somam-se ao aumento da densidade demográfica a desigualdade social e a possível corrupção de seus dirigentes. A corrupção como interferência se agrava e impede o desenvolvimento de uma nação, bem como interfere diretamente no bem-estar e na economia local (Campos \& Pereira, 2016). Por isso, pela via dos problemas, cidades brasileiras e indianas se aproximam em anseios. As tentativas de despoluição da Lagoa da Barra no Rio de Janeiro (Figura 10) e do Lago Kaikondrahalli (Bangalore), a popularização de avisos de poluição à população, a distribuição de renda e as tentativas de acompanhamento médico em periferias de famílias ausentes na rede pública comum reforçam essa hipótese.

Os problemas aproximam as realidades, muito mais do que distâncias geográficas ou de formação cultural. Ao se observar teóricos pós-colonialistas das Relações Internacionais, como Krishna (2009), as nações em desenvolvimento se assemelham e se colocam mais próximas em desafios locais e internacionais do que com as nações colonizadoras. Brasil e Índia passam a ter maior proximidade em desafios que superariam as distâncias culturais e geográficas, exigindo maior olhar entre as experiências positivas de gestão. Porém, a difusão dos modelos indianos no Brasil possui caminhos limitados ao contato entre cidades e suas respectivas trocas. Mais tradicionalmente, seria possível contar com a relação direta entre cidades brasileiras e indianas, o que não se vê nos registros municipais brasileiros das grandes cidades, como Rio de Janeiro e São Paulo. Já um outro caminho institucional mais fácil para essas difusões e trocas seriam as redes internacionais de cidades, como a Cidades e Governos Locais Unidos (CGLU). 


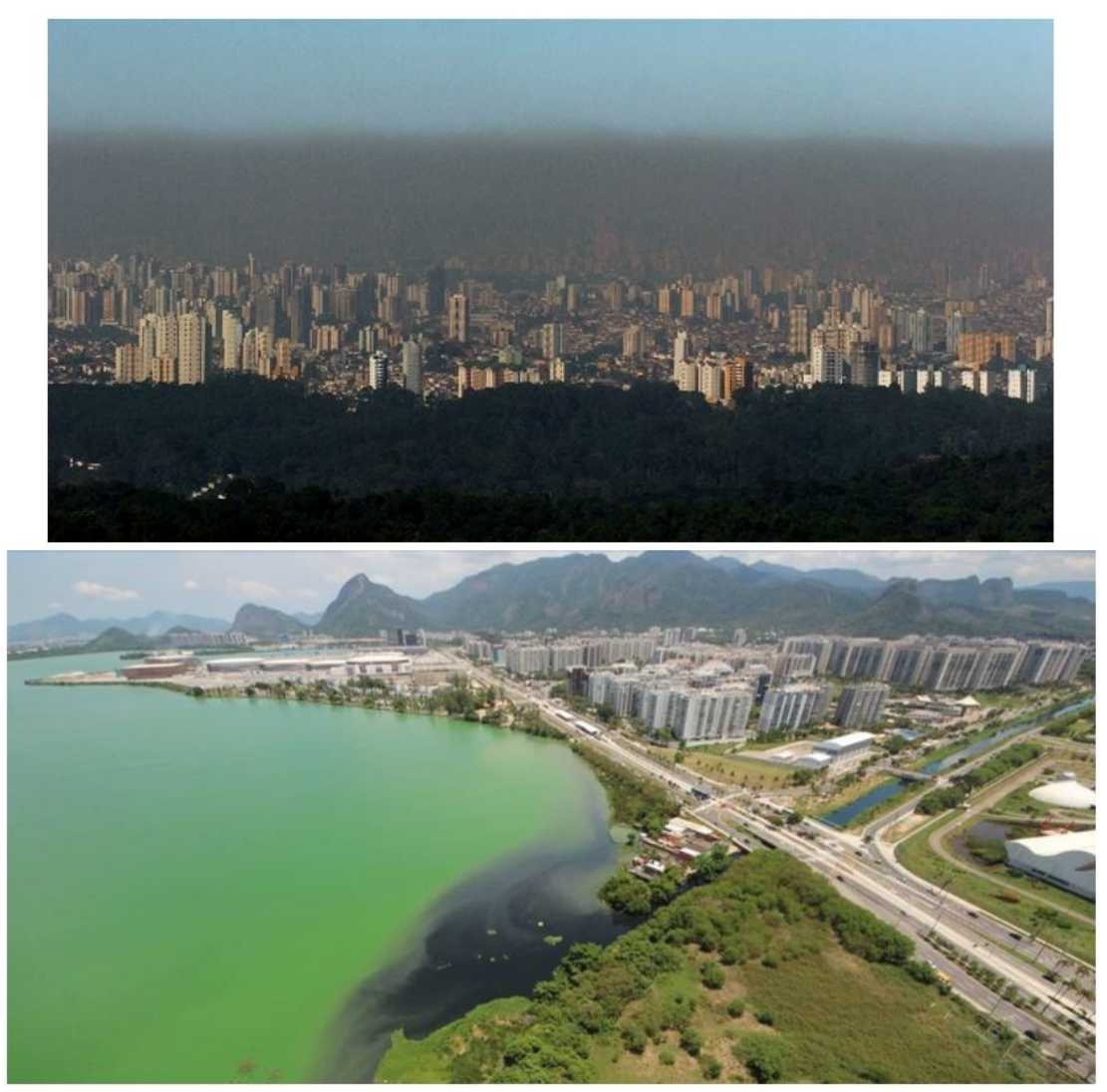

Figura 10 - Polvição na Lagoa da Tijuca no Rio de Janeiro e polvição do ar em São Paulo. Fontes: (Esq.) O Globo (2017) e (Dir.) Escobar (2014).

Na CGLU, contudo, ao observar os grupos de trabalhos, em um primeiro momento, não é possível identificar trocas e relações diretas entre cidades brasileiras e indianas, ainda que muitas façam parte dos grupos de trabalho da Agenda 21. A difusão, no entanto, pode ocorrer pelo simples fato das apresentações desses exemplos, como ocorre no material de divulgação do PNUD aos Estados-membros do Sistema ONU. Mas entre os governos nacionais receberem (como pela ONU ou pelo BRICS) e repassarem aos governos locais existe uma distância considerável que pode criar um hiato à difusão de boas práticas, especialmente no caso brasileiro, que tende a olhar para exemplos europeus conforme os acordos bilaterais e multilaterais presentes nos órgãos internacionais das cidades do Rio de Janeiro e de São Paulo.

Todavia, a relação entre Brasil e Índia, por meio das aproximações do BRICS, pode se tornar um canal viável à cooperação de governos locais para o desenvolvimento. Mas, assim como realidades próximas, Índia e Brasil também compartilham variáveis negativas já mencionadas, por exemplo, corrupção, pouco recurso financeiro para determinados setores de políticas públicas e ausência do governo em muitas regiões, como nas favelas. Segundo Dupont \& Saglio Yatzimirsky (2009), as dificuldades dos modelos neoliberais e da globalização aumentam os desafios sociais, ambientais e econômicos nas cidades indianas e brasileiras. Sassen (2011) também aponta para essa situação, pois, à medida que as grandes cidades globais surgem, as grandes favelas globais também. Os modelos de práticas neoliberais acentuaram as desigualdades, e hoje os governos locais em regiões em desenvolvimento demandam auxílio de cooperação com as sociedades locais e o capital privado. Conforme já mencionado, cidades em desenvolvimento tendem a olhar para cidades já desenvolvidas e se inserem em uma tentativa exaustiva em acompanhar ritmos e a perseguir índices sem ter os mesmos recursos, ferramentas e realidades socioculturais.

Produções locais, como as dos think tanks (grupos de conhecimento) em Relações Internacionais, também não dão muita evasão às práticas de gestão local em outras realidades. O CEBRI (Centro 
Brasileiro de Relações Internacionais), por exemplo, não possui em suas publicações eixos voltados à cooperação entre cidades e políticas locais brasileiras e indianas. Já o think tank BRICS Policy Center (parceria entre a Prefeitura do Rio de Janeiro e a PUC-Rio) possui maior espaço de publicações e análises nas relações entre Brasil e Índia. É possível identificar algumas publicações relevantes que podem auxiliar nessa aproximação entre cidades de ambos os países, especialmente no BRICS-Urbe.

Na publicação de 2011 denominada "Transformações políticas e urbanização na Índia: possibilidades e desafios" (BRICS Policy Center), pode-se ver um estudo sobre o crescimento urbano indiano e a relação social com castas, bem como outros temas locais que facilitam a compreensão brasileira das dinâmicas indianas e diminuem a distância psíquica ${ }^{3}$ entre gestores brasileiros quanto à realidade da Índia. Porém, apesar de ser um caminho possível para a difusão fora do eixo Brasil-Europa, apenas as publicações encontradas sobre a Índia não seriam suficientes para difundir modelos.

Em sua biblioteca virtual, o BRICS Policy Center possui algumas publicações sobre o tema Índia, como cooperação para a criação do Banco do Desenvolvimento do BRICS, cooperação no regime de propriedade intelectual, Índia e governança global para o clima, desenvolvimento sustentável na Rio+20 e processos de corrupção nos respectivos países mais África do Sul. Por isso, é possível dizer que, em uma observação breve, existe uma baixa produção dos think tanks (CEBRI e BRICS Policy Center) sobre práticas locais indianas e suas políticas públicas.

Ainda no caso dos think tanks, existe o relato das atividades do Practical Cooperation and Mutual Benefit, entre prefeitos das cidades de São Petersburgo, Mumbai, Rio de Janeiro e Qingdao em 2008. Mas, apesar da iniciativa de se abrir um canal entre as quatro cidades do BRICS, de concreto ocorreu a inauguração de uma praça da amizade (Praça das Cidades Parceiras BRIC em Huangdao) e trocas de experiências em apoio à indústria e ao setor privado, especialmente entre Rio de Janeiro e Qingdao no setor petrolífero e de oceano (Souza \& Werneck, 2011).

Trocas efetivas em políticas públicas de desenvolvimento humano, em um caminho mais cooperativo de práticas, não foram percebidas. Apenas trocas para fortalecer indústrias e comércios, como o turismo entre as cidades. Seria possível até olhar para outros think tanks, como os de gestão urbana, mas, ao limitar a área das Relações Internacionais aos estudos e às possibilidades de divulgação no Brasil de modelos internacionais de desenvolvimento local advindos do eixo sul-sul, como da Índia, são quase inexistentes aos internacionalistas que pesquisam e praticam a gestão urbana nas secretarias e coordenadorias municipais das grandes cidades (como a CRI no Rio de Janeiro).

Com isso, as cidades brasileiras - e seus gestores - perdem oportunidades de ter maior contato com experiências e boas práticas que se colocam como alternativas aos modelos europeus e de outras regiões desenvolvidas. Desafios socioeconômicos e demográficos distintos da realidade das nações desenvolvidas (que é o caso no Brasil) demandam possibilidades em contextos semelhantes. Entretanto, nem sempre os canais de estudos urbanos em Relações Internacionais, como os think tanks brasileiros CEBRI e BRICS Policy Center, estão em pleno funcionamento para motivar a difusão de boas práticas das grandes cidades no eixo sul-sul.

\section{Considerações finais}

O objetivo do presente artigo foi justificar o recorte de análise que defende o olhar para as boas práticas indianas em relação à gestão urbana e às medidas socioambientais das cidades brasileiras. A natureza semelhante nas esferas social, ambiental e política favorece e estimula mais análises comparadas entre as duas realidades. Com o advento do BRICS e de outras ferramentas de cooperação,

\footnotetext{
${ }^{3}$ Muito comum nos estudos sobre internacionalização de empresas, o termo distância psíquica seria o grau de conhecimento que um indivíduo teria de outras comunidades culturalmente distantes. Quanto maior o grau de conhecimento, menor é a distância psíquica e maior a probabilidade de se aproximarem e cooperarem. Segundo Figueiredo (2008, p. 3): "Para Fletcher e Bohn (1998, p. 49), 'a distância psíquica é questão de percepção - é uma distância na mente dos indivíduos e a distância percebida depende da maneira como os indivíduos veem o mundo"”.
} 
Brasil e Índia podem exercitar trocas positivas na solução e na superação de desafios comuns e semelhantes. Entretanto, como a própria pesquisa levanta, os mecanismos de diálogo, ao menos no campo das Relações Internacionais, ainda estão limitados às práticas nacionais - não tendo tanto espaço para as experiências subnacionais. Para que tal difusão possa ocorrer, é preciso rever os canais de comunicação que se mostram pouco abertos à relação das grandes cidades brasileiras e indianas, como os governamentais (BRICS, CGLU etc.) e os think tanks (grupos de conhecimento e suas publicações, por exemplo, o CEBRI e o BRICS Policy Center).

As práticas indianas aqui apresentadas demonstram uma característica dos modelos neoliberais, que é a responsabilização compartilhada do desenvolvimento entre governo, empresas e sociedade civil. Contudo, essa realidade, conhecida como parceria público-privada (PPP), ocorre muito mais por uma insuficiência de recursos dos governos em desenvolvimento e pelos processos da globalização financeira, conforme apontados por Sassen (2011). Um exemplo de desafios externos que se colocam às cidades seriam os processos intensos de favelização de muitas cidades no mundo (Sassen, 2011). Por isso, iniciativas indianas defendidas pelo PNUD, em sua maioria, acabam por difundir valores neoliberais em razão da ausência de recursos dos governos responsáveis. Todavia, ainda é valido reconhecer que muitas práticas não são competitivas, ou seja, não buscam fortalecer unicamente a própria cidade que as elabora, podendo as boas práticas serem replicadas em diversas realidades.

Nesse sentido, é possível dizer que, apesar de traços neoliberais, as boas práticas indianas também podem ter os valores cooperativos de desenvolvimento regional, de acordo com Mercher et al. (2018). Em uma possível relação sul-sul, as trocas de experiência podem superar desafios comuns, como as políticas de saúde, de gênero, ambientais e da informação. Deve-se ter em conta que a corrupção, apontada nas pesquisas do projeto SETUP (2009), também pode ser algo em comum em cidades em desenvolvimento que prejudica a cooperação e a aplicação de políticas públicas eficientes - e tanto a Índia como o Brasil possuem índices de corrupção relevantes que atrapalham a aplicação das boas práticas em suas regiões. Aproximações, como as PPP, podem ampliar processos de corrupção por trazer empresas (interesses privados) aos processos decisórios do interesse público, algo que os defensores dos modelos neoliberais ignorariam (Bresser-Pereira, 2009). Conclui-se defendendo que os estudos de gestão urbana podem fomentar o debate atual sobre possibilidades na gestão das grandes cidades brasileiras e seus desafios para além do eixo norte-sul.

\section{Referências}

Acharya, A. (2004). How ideas spread: whose norms matter? norm localization and institutional change in asian regionalism. International Organization, 58(2), 239-275. Recuperado em 23 de março de 2019, de http://www.ir.rochelleterman.com/sites/default/files/acharya\%202004.pdf

Actualitix (2016). Human development by country. Recuperado em 23 de março de 2019, de https://pt.actualitix.com/pais/wld/indice-de-desenvolvimento-humano-por-pais.php

Annenberg Learner (2015). Section 6: Urbanization and Megacities. In: Annenberg Foundation, Human Population Dynamics. Los Angeles: Annenberg Foundation. Recuperado em 23 de março de 2019, de https://www.learner.org/courses/envsci/unit/text.php?unit=5\&secNum=6\#worlds_largest_cities

Bresser-Pereira, L. C. (2009). Assalto ao Estado e ao mercado, neoliberalismo e teoria econômica. Estudos Avançados, São Paulo, 23(66), 7-23. http://dx.doi.org/10.1590/S0103-40142009000200002.

Campos, F. A. O., \& Pereira, R. A. C. (2016). Corrupção e ineficiência no Brasil: Uma análise de equilíbrio geral. Estudos Econômicos, São Paulo, 46(2), 373-408. Recuperado em 10 de janeiro de 2019, de http://www.scielo.br/scielo.php?script=sci_arttext\&pid=S0101-41612016000200373

City Mayors Statistics (2018). Largest cities in the World: Europe's largest cities ranked 1 to 100 \& US largest cities ranked 1 to 100. Londres. Recuperado em 31 de janeiro de 2019, de http://www.citymayors.com/features/euro_cities1.html. 
Dupont, V., \& Saglio-Yatzimirsky, M. C. (2009). Programas de erradicação, reassentamento e urbanização das favelas: Delhi e Mumbai. Estudos Avançados, 23(66), 283-302. Recuperado em 10 de janeiro de 2019, de http://www.scielo.br/scielo.php?script=sci_arttext\&pid=S0103-40142009000200020

Escobar, E. (2014, Março 25). Poluição do ar matou 7 milhões de pessoas em 2012, Estadão. Recuperado em 23 de março de 2019, de https://ciencia.estadao.com.br/blogs/herton-escobar/poluicao-do-ar-matou-7-milhoes-depessoas-em-2012/

Figueiredo, O. S. (2008). Distância psíquica e distância cultural: uma análise do domínio conceitual dos construtos. In Anais do XXXII Encontro Anual da ANPAD. Rio de Janeiro: ANPAD. Recuperado em 31 de janeiro de 2019, de http://www.anpad.org.br/admin/pdf/ESO-B1806.pdf

Governo da Índia. (2011). Provisional Population Totals, Census of India 2011; Cities having population 1 lakh and above. Índia: Office of the Registrar General \& Census Commissioner. Recuperado em 10 de janeiro de 2019, de http://censusindia.gov.in/2011-prov-results/paper2/data_files/India2/Table_2_PR_Cities_1Lakh_and_Above.pdf India Today (2013). India's second-richest state Delhi unable to feed its poor: DAY. Recuperado em 23 de março de 2019, de https://www.indiatoday.in/india/north/story/rti-dilli-annashree-yojana-dud-less-than-8000beneficiaries-india-today-161694-2013-05-04

Instituto Brasileiro de Geografia e Estatística - IBGE. (2010). CENSO 2010: Resultados do Censo Demográfico 2010. Rio de Janeiro: IBGE. Recuperado em 31 de janeiro de 2019, de https://censo2010.ibge.gov.br/resultados.html

Instituto Brasileiro de Geografia e Estatística - IBGE (2018). Estimativas da população residente nos municípios brasileiros com data referência em $1^{\circ}$ de julho de 2018. Brasília: Ministério do Planejamento, Desenvolvimento e Gestão. Recuperado em 31 de janeiro de 2019, de https://agenciadenoticias.ibge.gov.br/agencia-sala-deimprensa/2013-agencia-de-noticias/releases/22374-ibge-divulga-as-estimativas-de-populacao-dos-municipiospara-2018

Krishna, S. (2009). Globalization and Postcolonialism: hegemony and resistance in the twentyfirst century. Plymouth: Rowman \& Littlefield.

Malik, F. (2018, Maio 20). Maharashtra govt to rehabilitate all ineligible slum dwellers in Mumbai; but for at a cost. Hindustan Times. Recuperado em 23 de março de 2019, de https://www.hindustantimes.com/mumbainews/maharashtra-govt-to-rehabilitate-all-ineligible-slum-dwellers-in-mumbai-but-for-at-a-cost/storyuBHcbi5tfZz3KJWyRB6G8N.html

Maricato, E. (2000). Urbanismo na periferia do mundo globalizado: metrópoles brasileiras. São Paulo em Perspectiva, 14(4), 21-33. http://dx.doi.org/10.1590/S0102-88392000000400004.

Maziviero, M. C., \& Silva, A. S. (2018). 0 caso do Complexo Paraisópolis em gestões: diferenças conceituais em programas de intervenção em favelas em São Paulo. URBE, 10(3), 500-520. http://dx.doi.org/10.1590/21753369.010.003.ao03.

Mercher, L., Bernardo, G., \& Silva, E. Z. (2018). Difusão internacional de modelos de desenvolvimento na Rede de Mercocidades. Revista de Estudos Internacionais, 9(2), 65-87. Recuperado em 10 de janeiro de 2019, de http://www.revistadeestudosinternacionais.com/uepb/index.php/rei/article/view/387/387

Nagendra, H. (2016). Restoration of the Kaikondrahalli lake in Bangalore: Forging a new urban commons. Pune: Azim Premji University. Recuperado em 10 de janeiro de 2019, de http://www.vikalpsangam.org/static/media/uploads/Resources/kaikondrahalli_lake_casestudy_harini.pdf

O Globo. (2017, 31 de janeiro). A poluição nas lagoas da Barra e Jacarepaguá. [Galeria de fotos de Mário Moscatelli]. Recuperado em 23 de março de 2019, de https://oglobo.globo.com/rio/a-poluicao-nas-lagoas-da-barrajacarepagua-20846290

Peer Expierience and Reflective Learning - PEARL. (2015). Urban Water Supply and Sanitation in Indian Cities (Compendium of Good Practices). New Delhi: National Institute Urban Affairs. Recuperado em 23 de março de 2019, de https://citynet-ap.org/the-peer-experience-and-reflective-program-pearl/ 
Pereira, A., Bernardo, G., Culpi, L., \& Pessali, H. (2018). A governança facilitada no Mercosul: transferência de políticas e integração nas áreas de educação, migração e saúde. Revista de Administração Pública, 52(2), $285-302$. Recuperado em 18 de fevereiro de 2019, de http://www.scielo.br/scielo.php?pid=S0034$76122018000200285 \&$ script=sci_abstract\&tlng=pt

Programa das Nações Unidas para Habitação - UN-Habitat. (2005). Porcentagem da população mundial vivendo em favelas. New York: UN. Recuperado em 23 de março de 2019, de http://www.unhabitat.org/stats/Default.aspx

Sánchez, F. (2001). A reinvenção das cidades na virada do século: agentes, estratégias e escalas de ação política. Revista Sociologia \& Política, 3(16), 31-49. Recuperado em 31 de janeiro de 2019, de http://www.scielo.br/pdf/rsocp/n16/a03n16.pdf

Sassen, S. (2011, Abril 8). Curfew in the Favela. Forbes. Recuperado de 10 de janeiro de 2019, de https://www.forbes.com/sites/megacities/2011/04/08/curfew-in-the-favela/\#633482706bc7

Social Exclusion, Territories and Urban Policies - SETUP (2009). SETUP: A comparison between India and Brazil Recuperado em 23 de março de 2019, de http://www.csh-delhi.com/team_member/veronique-dupont/

Souza, N. M. F., \& Werneck, M. (2011). BRICS Monitor: Mecanismos de cooperação entre cidades no âmbito BRICS. Rio de Janeiro: BRICS Policy Center. Núcleo de Desenvolvimento Urbano e Sustentabilidade.

Stone, D. (2012). Transfer and translation of policy. Journal Policy Studies, 33(6), 483-499. http://dx.doi.org/10.1080/01442872.2012.695933

Transparency International Georgia. (2014). Georgia ranks 50th among 175 countries in the 2014 Corruption Perceptions Index. Tbilisi: Transparency International Georgia. Recuperado em 23 de março de 2019, de https://www.transparency.ge/en/post/corruption-perception-index-cpi-2014

United Nations Development Programme - PNUD \& Government of India. (2015). Social Sector Service Delivery: Good Practices Resource Book 2015. New York: PNUD; Government of India. Recuperado em 10 de janeiro de 2019, de http://www.in.undp.org/content/india/en/home/library/democratic_governance/SSS-delivery-goodpractices-2015.html

World Meteorological Organization - WMO. The GAW Urban Research Meteorology and Environment Project of World Meteorology Organization - GURME. (2018). SAFAR India Commonwealth Games. Recuperado em 10 de janeiro de 2019, de http://mce2.org/wmogurme/projects/india-commonwealth-games

Editor: Janaína Pasqual Lofhagen.

Recebido: Jan. 10, 2019

Aprovado: Fev. 20, 2019 